\title{
Application of fruit traits to the taxonomy of the genus Geranium L. by means of section Recurvata as an example
}

\author{
Viktoriya I. Troshkina \\ Central Siberian Botanical Garden of SB RAS, 630090 Novosibirsk, Russia
}

\begin{abstract}
Using the section Recurvata (Knuth) Novosselova as an example, this article discusses specific features of morphological traits of the mericarp surface in species of the genus Geranium L. and application of these traits to the taxonomy of the genus. It is shown that the traits of the mericarp surface are distinguishing features of subsections and species. The distinguishing features at the subsection level include the presence or absence of crinkles on the mericarp as well as its size. The distinguishing feature at the species level is the type of mericarp pubescence.
\end{abstract}

\section{Introduction}

For a more complete understanding of taxon boundaries, it is necessary to search for additional identifying traits. In this regard, morphological structure of the mericarp surface has been indirectly mentioned by various authors [1-4 and others]; however, no specific studies have been conducted. In our previous research [5, 6], I have also examined the application of fruit morphological traits to the taxonomy of the genus Geranium using some groups of species as an example.

In this work, I analyze the traits of mericarp morphological structure in taxa of the section Recurvata (Knuth) Novosselova. In the genus in question, this is one of the key sections because its taxa are widespread throughout Eurasia, serve as important components of many plant communities, and are complex taxa in the diagnostic sense. The species studied here are classified into two subsections: Recurvata Knuth (G. pratense L., $G$. sergievskajae [Peschkova] Troschkina, G. affine Ledeb., and G. transbaicalicum Serg.) and Collina Knuth (G. collinum Steph. ex Willd. var. eglandulosum Ledeb., G. collinum Steph. ex Willd. var. glandulosum Ledeb., G. saxatile Kar. et Kir., G. regelii Nevski, and G. pamiricum Ikonn.).

\section{Material and methods}

Mericarps for the comparative morphological analysis of the traits were taken from specimens from the following herbaria: M.G. Popov Collection (Novosibirsk, NSK), I.M. Krasnoborov Collection (Novosibirsk, NS), the Collection at V.L. Komarov Botanical Institute (Saint-Petersburg, LE), and D.P. Syreishikov Collection at Moscow State University (Moscow, MW). 
The surface of the mericarps was analyzed under a scanning electron microscope (EVO MA 10, Carl Zeiss) in the Central Siberian Botanical Garden SB RAS (Novosibirsk, Russia). The mericarps were attached to the microscope stage with adhesive tape, and gold was sputtered with a Mini SC 7620, followed by scanning.

\section{Results and discussion}

All the studied taxa are characterized by sterigma with ribbonlike appendages separating but merged at the apex. The mericarps are dehiscent, with hairs (trichomes) at the base. Representatives of the subsection Recurvata are characterized by mericarps slightly wrinkled at the apex, whereas Collina representatives by mericarps smooth at the apex. This trait can be considered a distinguishing feature at the subsection level. Mericarp size can also be a distinguishing feature at the subsection level: the mericarps of Recurvata taxa subsection are larger than those of Collina taxa.

Traits at the species level include the type of mericarp pubescence. This trait is auxiliary and can be used in difficult diagnostic cases when there is a question about assigning a realworld specimen to a particular taxon among closely related species. All the analyzed taxa have capitate unbranched short hairs with a 1-3(4)-cell stalk and unicellular head. Most often, these hairs have a 2-cell stalk. Their length is $0.097 \pm 0.040 \mathrm{~mm}$, and they can be distinguished only at the high magnification of a scanning electron microscope.

We studied four species from the subsection Recurvata (Fig. 1, 1-4). A distinctive feature of $G$. pratense L. mericarp pubescence is the presence of complex single-row filamentous cobwebby trichomes (Fig. 2, 1). We noted similar trichomes in several other species of the genus Geranium, but in the section Recurvata, they can be found only in $G$. pratense. Besides, the mericarps of this species are smaller than those of other species from the subsection Recurvata.
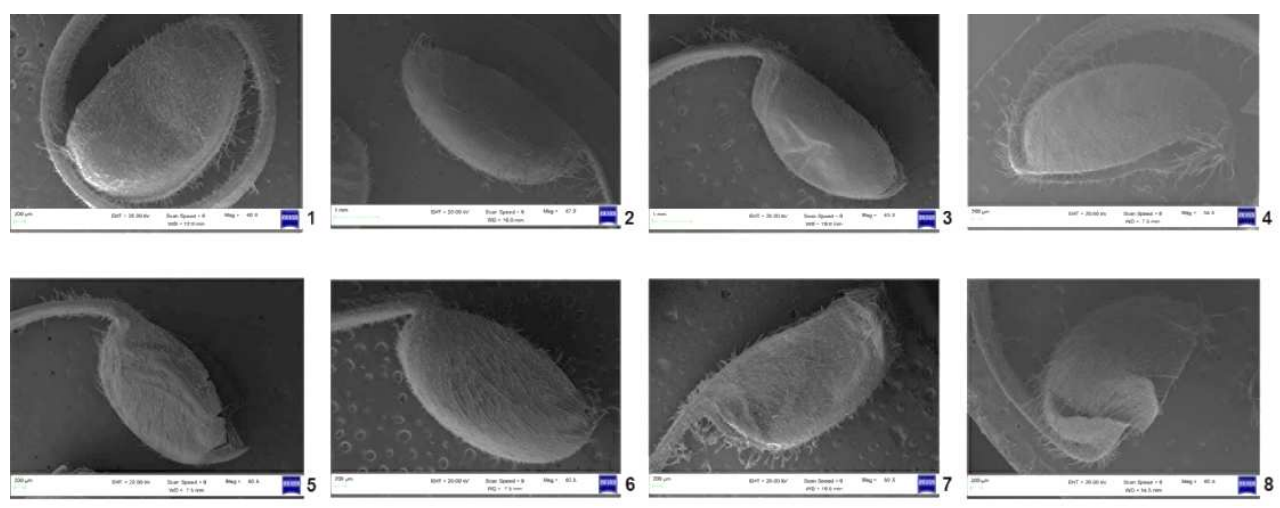

Fig. 1. Mericarp shapes in species of the genus Geranium, section Recurvata. Panel 1: G. pratense, 2: G. sergievskajae, 3: G. affine, 4: G. transbaicalicum, 5: G. collinum, 6: G. saxatile, 7: G. regelii, and 8: G. pamiricum.

G. sergievskajae (Peschkova) Troschkina mericarps are characterized by only one type of nonglandular trichomes (simple unicellular unbranched conical hairs, which can be short or long) and by three types of glandular trichomes (Fig. 2, 2). One of these types (capitate unbranched long hairs with a 2-3-cell stalk and unicellular head without a collar) is characteristic only of $G$. pratense and G. sergievskajae. It was not found in other taxa of this section.

On G. affine L. mericarps, there is only one type of glandular trichomes (capitate unbranched short trichomes with a 1-3(4)-cell stalk and unicellular head), which, as already 
mentioned, are distinguishable only at high magnification. Therefore, the absence of glandular pubescence on the mericarps can be helpful for identifying this species in laboratory settings. Furthermore, in the subsection Recurvata, this is the only species that has simple unicellular unbranched awl-shaped straight hairs (Fig. 2, 3).

Mericarp pubescence in the species $G$. transbaicalicum also consists of only one type of nonglandular trichomes. Nonetheless, in its glandular pubescence, there is a subtype of trichomes: capitate unbranched short hairs with a 2-cell stalk and wide unicellular head (Fig. 2, 4).
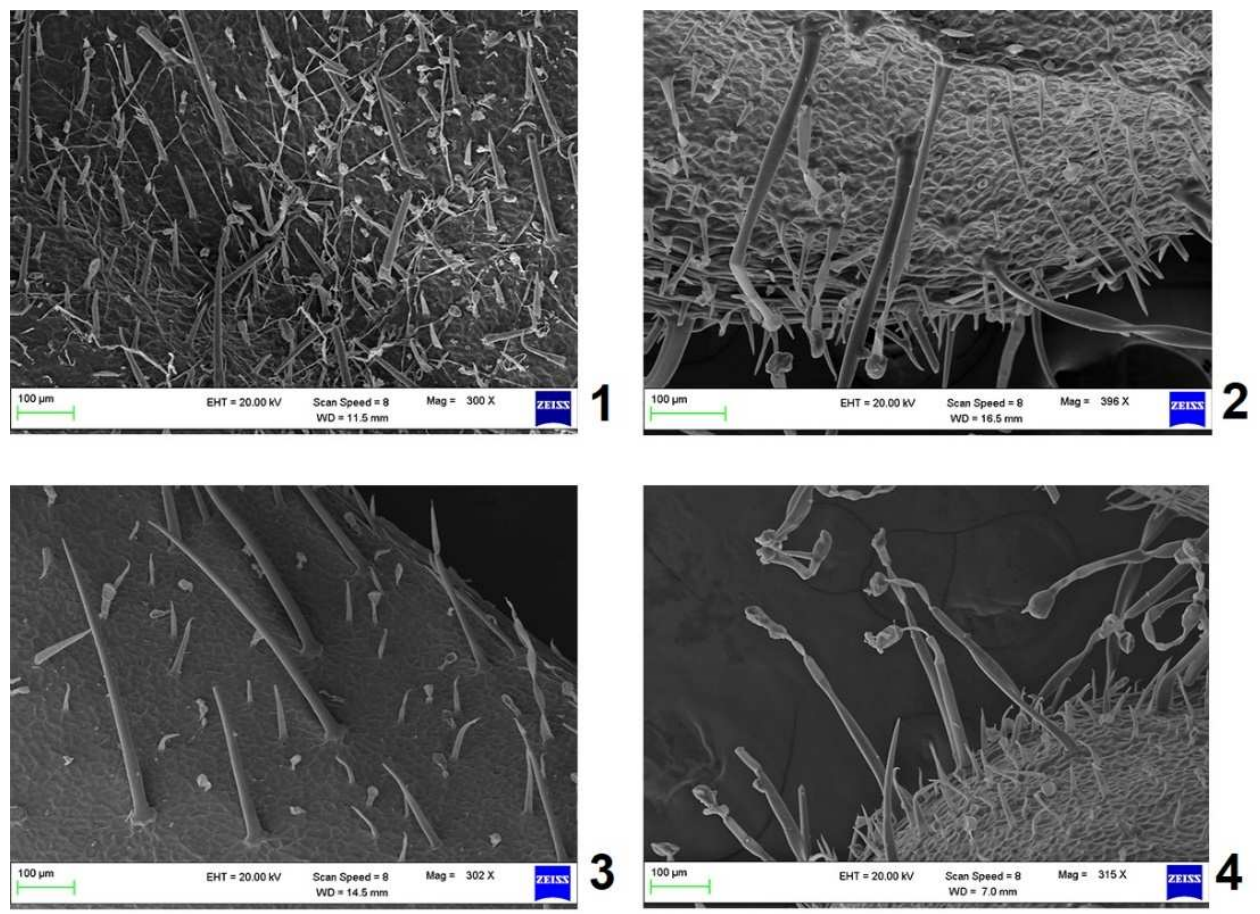

Fig. 2. Specific features of mericarp pubescence in Geranium species of the section Recurvata, subsection Recurvata. Panel 1: G. pratense, 2: G. sergievskajae, 3: G. affine, and 4: $G$. transbaicalicum.

Therefore, mericarp pubescence is quite diverse among the species of the subsection Recurvata. The types of trichomes that are common to all these species are simple unicellular unbranched conical hairs (short and long) and capitate unbranched short hairs with a 1-3(4)-cell stalk and unicellular head.

In the subsection Collina, we analyzed four species too (Fig. 1, 5-8), including two varieties of G. collinum: var. eglandulosum and var. glandulosum. The mericarps of both varieties are hemispherical and differ in the types of nonglandular trichomes: mericarps of var. eglandulosum are covered with simple unicellular unbranched awl-shaped straight hairs of various lengths (from very short to very long), whereas mericarps of G. collinum var. glandulosum are covered with short and long simple unicellular unbranched conical hairs and simple unicellular unbranched ribbonlike hairs. The latter type has so far been found only in this variety and has not been previously reported for geraniums (Fig. 3, 1).

The mericarps of $G$. saxatile are distinguished from those of other Collina species by their ellipsoidal shape (Fig. 1, 6). In the other species, the mericarp is hemispherical. Mericarp pubescence in G. saxatile is similar to that in G. regelii (Fig. 3, 2 and 3). The 
mericarps of the latter are distinguished from those of the other species in this subsection by large size (Fig. 1, 7).

G. pamiricum mericarps are rather small and carry only two types of trichomes in their pubescence: unicellular unbranched conical hairs (short and long) and capitate unbranched short hairs. The latter are not visible under a binocular microscope thereby giving the impression of the absence of glandular pubescence (Fig. 3, 4).
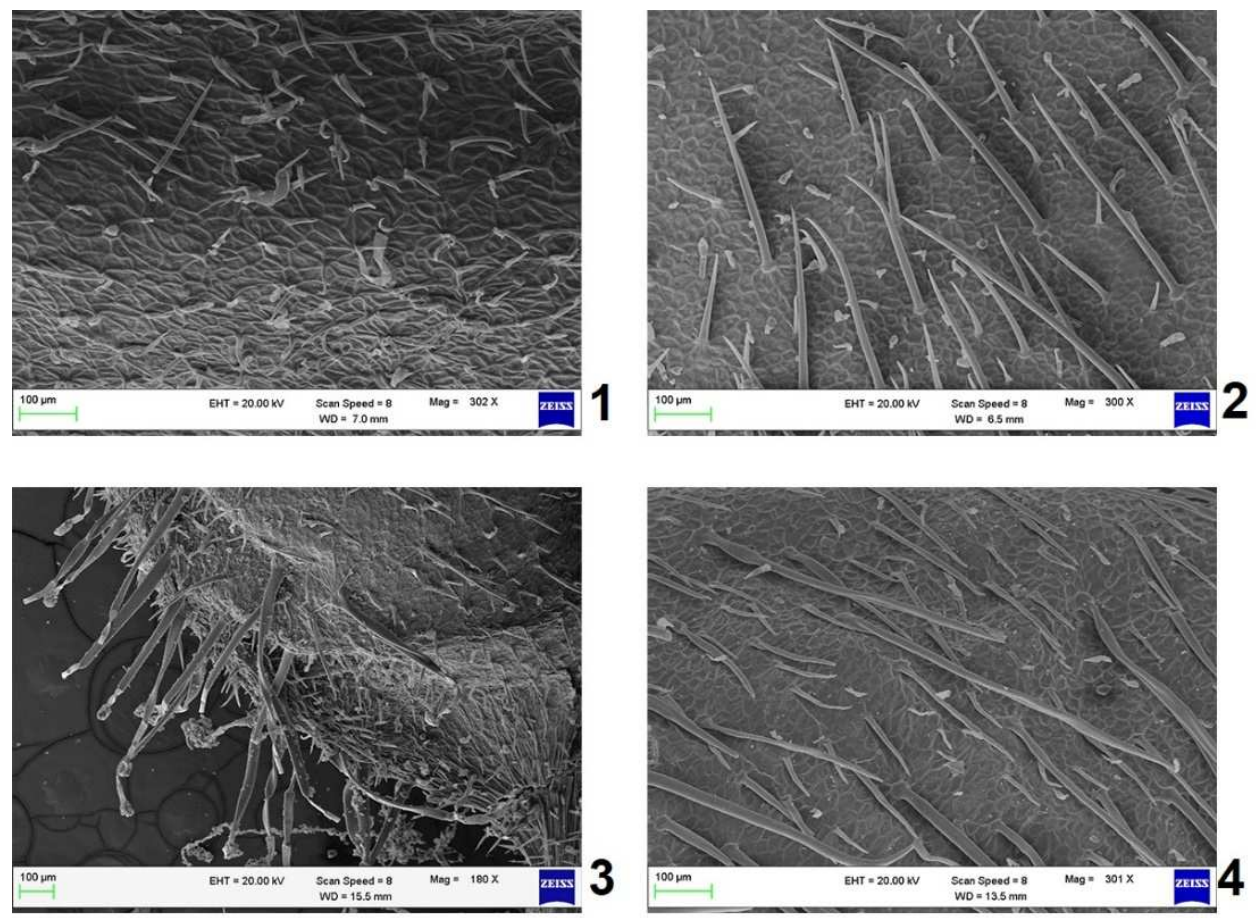

Fig. 3. Specific features of mericarp pubescence in Geranium species of the section Recurvata, subsection Collina. Panel 1: G. collinum, 2: G. saxatile, 3: G. regelii, and 4: G. pamiricum.

Thus, mericarp pubescence of the species in the subsection Collina is less diverse than that in the subsection Recurvata. All the species also possess capitate unbranched short hairs with a 1-3(4)-cell stalk and unicellular head. Almost all the species have simple unicellular unbranched conical hairs (short and long), and most of the species have simple unicellular unbranched awl-shaped straight hairs.

\section{Conclusion}

The section Recurvata is classified into two subsections: Recurvata and Collina; in each, mericarps were examined in four species. The feature common to all the studied taxa (not only in this section) is the presence of capitate unbranched short hairs with a 1-3(4)-cell stalk and unicellular head. This trait can be regarded as a distinguishing feature at the genus level. We documented distinguishing features at subsection and species levels too. The distinguishing features at the subsection level include the presence or absence of crinkles on the mericarp as well as its size. The distinguishing feature at the species level is the type of mericarp pubescence.

The author is sincerely grateful to I.V. Eremin for the help with the scanning of the samples by means of the scanning electron microscope. The English language was 
corrected and certified by shevchuk-editing.com. This research was performed within the framework of a state assignment for the Central Siberian Botanical Garden SB RAS (No. AAAA-A21-121011290024-5). During the preparation of this publication, the scientific collection and the bioresource database of the Central Siberian Botanical Garden SB RAS ["Herbarium of vascular plants, lichens, and fungi (NS, NSK)," unique scientific unit No. 440537] were used.

\section{References}

1. C. Aedo Anales Jardin botanico de Madrid, 58(1) (2000)

2. Ch.-H. Chen, Ch.-M. Wang, Taiwania, 52(3) (2007)

3. P. F. Yeo, Bot. J. Linn. Soc. 89 (1984)

4. P. F. Yeo, Bot. 49 (1992)

5. V. I. Troshkina, Flora and Vegetation of Asian Russia, 27(3) (2017)

6. V. I. Troshkina, BIO Web of Conferences, 24 (2020) 